\title{
INTELIGÊNCIA EMOCIONAL E O DESENVOLVIMENTO DE COMPETÊNCIAS SOCIOEMOCIONAIS NA FORMAÇÃO DO PROFESSOR
}

\section{ARTIGO DE REVISÃO}

KOBARG, Ana Paula Ribeiro ${ }^{1}$

KOBARG, Ana Paula Ribeiro. Inteligência Emocional e o Desenvolvimento de Competências Socioemocionais na Formação do Professor. Revista Científica Multidisciplinar Núcleo do Conhecimento. Ano 04, Ed. 10, Vol. 02, pp. 35-53. Outubro de 2019. ISSN: 2448-0959, Link de acesso: https://www.nucleodoconhecimento.com.br/educacao/competenciassocioemocionais

\section{RESUMO}

A escola hoje deve ser vista como um espaço de relacionamento entre pessoas que pensam, de profissionais que necessitam de qualidade de vida e saibam administrar estes pensamentos, situações e reações emocionais. Este artigo traz uma reflexão sobre a prática docente no âmbito das emoções, temática tão necessária na sociedade contemporânea. Espera-se que a explanação realizada neste artigo, com base nas referências teóricas analisadas, venha contribuir para a discussão sobre a importância de repensarmos a educação no contexto brasileiro, e principalmente sobre a competência emocional do educador. Conclui-se que a educação assim repensada e compreendida desencadeia um processo refletido das relações entre compromisso ético e o fazer pedagógico, através de uma prática educativa que

1 Doutora em Psicologia- UFSC, SC/Br; Professora do curso de Psicologia da Fameblu- Faculdade Metropolitana de Blumenau. SC/BR; Pós-doutoranda em Educação pela FCU- Flórida Christian University- Orlando- USA. 
interfira em nosso conhecimento, em nossas possibilidades, como aprendizes e ensinantes, em uma mistura de ação e aprendizagem.

Palavras-chave: Inteligência Emocional, competências socioemocionais, professores.

\section{INTRODUÇÃO}

Nas últimas décadas, as discussões e práticas sobre a formação de professores tem sido assunto de inúmeros congressos, pesquisas e políticas públicas para a educação (BAUER, CASSETTARI E OLIVEIRA, 2017). No entanto, percebe-se que as mudanças no processo formativo dos atuais e futuros professores ainda são pequenas, uma vez que não há foco em uma formação que resultasse na valorização da "pessoa" professor, em um processo de autoconhecimento e que em consequência poderia acarretar uma melhora na educação brasileira. Moraes et al (2012) aponta que as iniciativas de formação contínua de professores ocorridas nas décadas de 1970 a 1990 foram pouco eficazes na transformação das concepções, dos conhecimentos e da prática docente. O modelo mais comum visto na história da educação brasileira de formação de professores mostra iniciativas de renovação pedagógica, realizadas insistentemente ao longo dos anos, isto é, cursos com objetivo de atualização da formação inicial ou reciclagem, capacitação e qualificação ou aperfeiçoamento profissional.

O termo capacitação remete a uma reflexão, quando se observa o significado da palavra no dicionário: "Capacitar: 1 - Tornar ou tornar-se capaz. 2 - Acreditar ou fazer acreditar." Quando é analisado seu antônimo: "Inapto, incapaz, incapacitado, inábil, incompetente, inepto, imperito, ineficaz, inútil, insuficiente, impossibilitado." (AURÉLIO, 2018). O que vemos nas entrelinhas é um discurso que vem contribuindo para a desvalorização do professor e até mesmo a construção negativa do seu autoconceito profissional: Sou incapaz!

Foucault (1970) discorre sobre o quanto a ligação saber-poder é determinante. Para ele, não há como falar de poder sem explicar os discursos que o legitimam, assim como não é possível falar de saber sem explicar as relações de poder que são 
movidas pelos discursos. Saber e poder são palavras de conceitos separados, mas são a mesma coisa na vida cotidiana. Então, em decorrência de anos de desmotivação e desvalorização, temos hoje um professor que não acredita em si mesmo.

As propostas de formação contínua se restringem à renovação de conhecimentos, muitas vezes sem articulação com o trabalho realizado em sala de aula, ou ainda "modismos", onde fazem o professor abandonar o que sabe e aventurar-se no mundo de metodologias diferenciadas, sem aprofundamento ou reflexão. Nesse modelo de formação desconsideram-se o professor como um produtor de conhecimento. Outro ponto a destacar é que a formação de professores não se constitui como um processo contínuo; ao contrário, ocorre de forma irregular, em formações rápidas (de 1 ou 2 dias), frequentemente não fazem parte de uma política pública efetiva para desenvolvimento de professores, ou ainda melhora do nosso sistema educacional. (ROSIN-PINOLA; DEL PRETTE, 2014)

Sabe-se que o trabalho pode levar um pedágio emocional, navegar em turbulentas dinâmicas de equipe, gerenciar conflitos e resolver problemas sob pressão pode se tornar emocionalmente desgastante. Todo professor sente isso e é algo que deve preocupar, porque dita o estado emocional das salas de aula para melhor ou para pior. Essa é uma tarefa inconsciente e primordial da docência.

Moraes et al (2012) aponta que essa situação é desgastante em trabalhos que exigem o que os cientistas sociais chamam de "trabalho emocional", tendo que parecer estar em um estado emocional positivo quando não o sentimos. Isso vale particularmente, por exemplo, em empregos de varejo e food service, onde slogans como "serviço com um sorriso" e "o cliente tem sempre razão" transmitem a exigência de que os funcionários expressem emoções desejadas socialmente e aceitem as demandas do cliente apesar de quaisquer verdadeiros sentimentos sentidos por eles. O professor também faz muito trabalho emocional, por isso vivenciam perturbações constantes, como raiva, tristeza ou angústia, fazendo efetivamente parte do seu trabalho. 
Talvez não seja nenhuma surpresa que pessoas com alta inteligência emocional (El) tenham um desempenho melhor em tarefas tão exigentes do ponto de vista emocional e tenham menor probabilidade de experimentar o esgotamento ao longo do tempo (GOLEMAN, 2012, 2017). Portanto, à docência requer um trabalho emocional extra, o desenvolvimento de pontos fortes em competências específicas de inteligência emocional pode melhorar seu desempenho e ajudar a sustentar sua saúde emocional. Por exemplo, a autoconsciência emocional e o autocontrole emocional ajudam a reconhecer os sentimentos e a administrá-los melhor em situações difíceis, como tratar um aluno, uma família problemática.

Portanto, uma formação em inteligência emocional é um modelo complexo, porém viável, pois deve envolver diferentes teorias e técnicas tanto psicológicas, psicopedagógicas, quanto pedagógicas. Devem estar relacionadas ao âmbito social, comportamental e cognitivo do indivíduo, possibilitando uma compreensão com múltiplas formas de pensar o fazer, ser e sentir-se docente. A formação em Inteligência emocional pode ser utilizada em distintos locais e problemáticas, sendo seu uso de suma importância, pois tem como objetivo realizar prevenção, promoção e educação em saúde (CHIEN, 2008; RAHMANI ET AL., 2015).

A Saúde Mental é um estado de bem-estar em que o indivíduo pratica as suas capacidades, enfrenta o estresse normal da vida, trabalha produtivamente e com sucesso, e é capaz de contribuir para a sua comunidade (WHO, 2001).

A pertença deste artigo reside na acuidade da promoção da saúde mental com base na aquisição de competências socioemocionais. Lehtinen (2008) descreve que o desenvolvimento de competências pessoais, tais como o autoconhecimento, a autoestima, a auto eficácia, as relações interpessoais e competências comunicacionais, a resolução de problemas, promovem a melhoria da saúde mental e ajudam as pessoas a exercer mais autonomia sobre a sua vida e sobre o ambiente em que vivem. 
Hoje e sempre, a profissão de professor é delicada e complexa. Vive-se um momento histórico, de crise social e ambiental, e os professores exercem a sua profissão em sociedades cada vez mais abertas e cheias de desequilíbrios. Ainda convivem no meio de sucessivas reformas educacionais, que buscam sempre um foco nas necessidades dos alunos e pais. E o professor, como fica?

Os professores desempenham um papel importante na vida das crianças. Além de facilitar o aprendizado, os professores são agentes-chave da socialização, ajudando os alunos a alcançarem seu potencial mais elevado e se transformando em cidadãos responsáveis. Mas, nos últimos anos, o ensino tornou-se cada vez mais estressante.

Hoje, o ensino é uma das ocupações mais estressantes nos EUA (JOHSON, KRAFT e PAPAY, 2012). O estresse do professor afeta sua saúde e bem-estar, as atitudes no trabalho (por exemplo, a satisfação no trabalho) e a rotatividade.

O estresse do professor normalmente está ligado ao desempenho do ensino e aos resultados acadêmicos dos alunos. Altos níveis de estresse estão fazendo com que os professores deixem sua profissão, o que causa instabilidade entre os funcionários, alunos e a comunidade. Em resposta, as escolas e órgãos públicos estão contratando novos professores com menos experiência, resultando em menor aproveitamento dos alunos e custos significativos de treinamento para os sistemas escolares.

Surgem diversas discussões sobre inteligência emocional, humanização no trabalho (COBERO e MUNIZ, 2006; COSTA e FARIA, 2012; FOSENCA et al, 2016; GOUVEIA, 2016; VALE, 2009). Hoje há urgência em tentar compreender o comportamento humano, no seu agir e no seu sentir, pois há inúmeras pessoas com problemas emocionais, principalmente relacionados ao trabalho. Sendo assim, Goleman (2006, p. 54) explana o conceito de Inteligência Emocional como:

a capacidade de a pessoa se motivar a si mesma e persistir a despeito das frustrações: de controlar os impulsos e adiar a recompensa; de regular o seu próprio estado de espírito e impedir que o desânimo subjugue a faculdade de pensar; de sentir empatia e de ter esperança. 
A partir desse conceito de Goleman (2006) o professor acaba assumindo uma grande responsabilidade, pois lida com a formação intelectual e emocional de crianças, adolescentes e até adultos. Estrela (2010) e Coelho (2012) colaboram apontando que a percepção que o professor tiver da sua história de vida, ou seja, seu autoconhecimento, poderá ajudar a lidar de forma eficiente com as dúvidas e equívocos no exercício da docência, e, por consequência, ter condutas mais adequadas.

O Plano Nacional de Saúde Escolar, segundo IBGE (2012, p. 22), é ainda mais específico, aludindo o implemento de programas "dando prioridade a novas áreas de formação, como as metodologias de intervenção ativas-participativas, o trabalho interpares, e a promoção de competências pessoais e sociais, pelo potencial de comunicação interpessoal que promovem na escola".

Uma formação em Inteligência Emocional pode ser o vetor para uma mudança significativa nas relações que se estabelecem no espaço educacional, pois, como educador, o professor é uma figura modelo para o aluno. Veiga Branco (2005) refere que as alterações emocionais do professor no cotidiano escolar podem, e na maioria das vezes acabam desencadeando emoções e comportamentos reativos nos alunos, e este processo nos faz destacar o quanto se faz necessário e importante uma formação para o desenvolvimento de competências e habilidades socioemocionais para o professor.

Num estudo nacional com professores de Portugal, Veiga Branco (2005) conclui que há fatores que merecem destaque no repensar a educação, um deles é que o adulto de amanhã depende e se constrói nas escolas do presente, e no presente as escolas estão atreladas aos professores que assumem papel importante, operacionalizar de forma ativa, o que lhe é atribuído: uma educação de qualidade.

Fenández-Berrocal e Extremera (2002) vinculam a competência do professor como aquele que apreende, percebe e auxilia as emoções dos seus alunos, e em consequência obtém uma melhora no equilíbrio emocional dos mesmos. 


\section{INTELIGÊNCIA EMOCIONAL}

A inteligência emocional ficou conhecida nas duas últimas décadas, em especial após a publicação do livro Inteligência Emocional de Daniel Goleman. Tem sido intitulada de "a inteligência do século XXI", substituindo a inteligência baseada no coeficiente intelectual quantificado por meio de testes de QI (Quociente de Inteligência), que foram originalmente elaborados por Binet e Simon em 1905 e que, até então, eram amplamente aceitos. (GOLEMAN, 2006)

Um novo conceito é debatido - o QE (Quociente Emocional). O desenvolvimento do Quociente Emocional envolve cinco áreas: a) a identificação - é a área da autoconsciência, da habilidade para reconhecer e compreender seus próprios sentimentos e emoções e os efeitos deles nas outras pessoas; b) a conscientização é a área da autorregulação, da capacidade de pensar antes de agir, de compreender porque age de uma determinada maneira e de controlar e trabalhar as emoções negativas, c) a atitude - é a capacidade de pensar positivo e com otimismo, d) a empatia - é a área da habilidade de compreender as emoções do outro e saber utilizar esse conhecimento ao se relacionar, e) a comunicação positiva - que se relaciona com a socialização, ou seja, é a habilidade do indivíduo de se relacionar bem com os outros criando uma grande rede de relações em que é compreendido e busca compreender. (GARDNER, 2000; GOLEMAN, 2012) 
Figura 1: Competências de Inteligência Social e Emocional

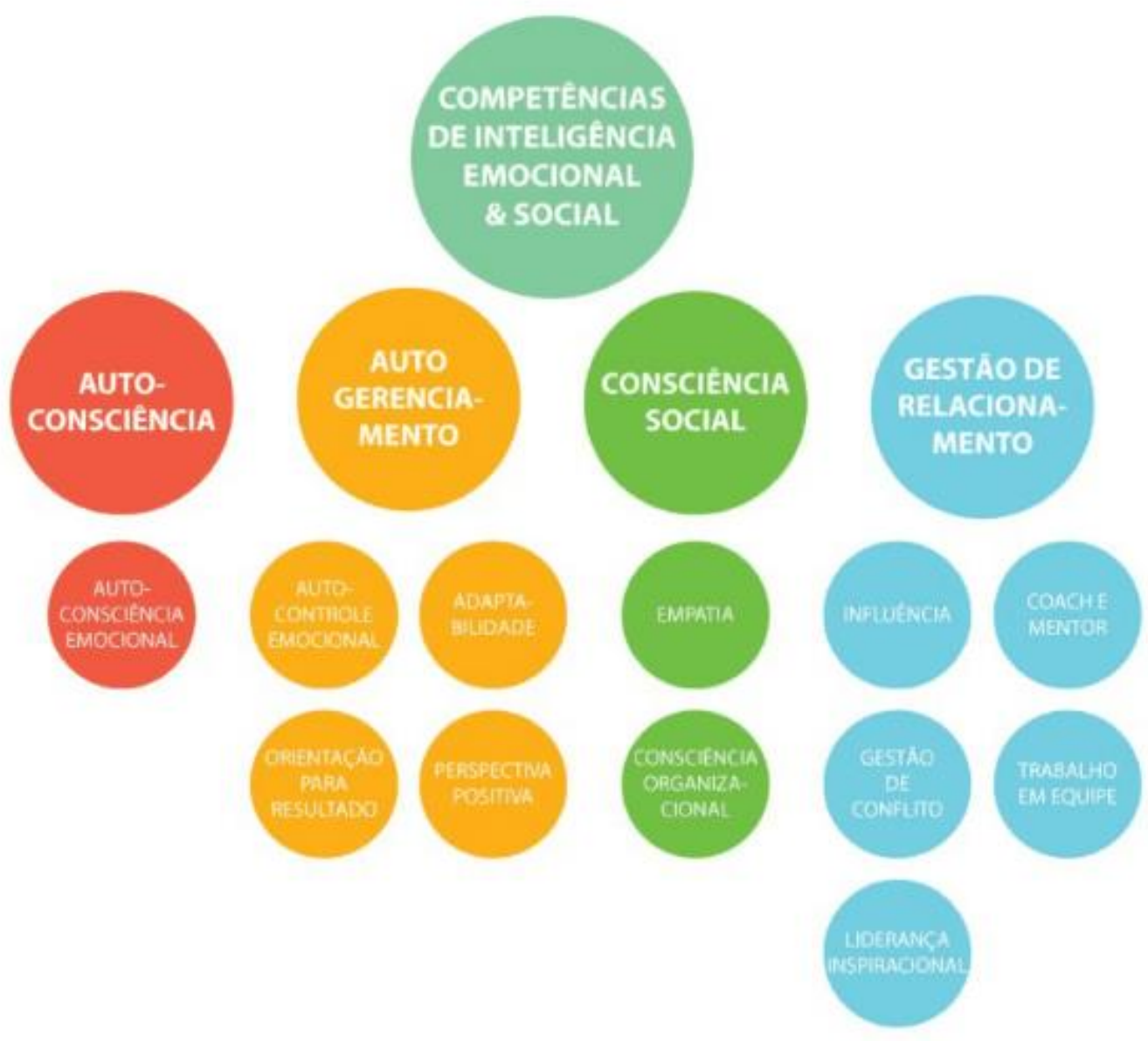

(GOLEMAN, 2017)[/caption]

Goleman (2006) ensina que o controle das emoções é essencial para o desenvolvimento da inteligência de um indivíduo. Não tem a ver com sorte genética que define quem vence e quem perde no jogo das relações e, embora existam pontos que determinam o temperamento, muitos dos comportamentos (circuitos cerebrais da mente humana) são adaptáveis e podem ser trabalhados. Portanto, temperamento não é destino. 
Goleman (2012) define a Inteligência Emocional como a "capacidade de identificar os nossos próprios sentimentos e os dos outros, de nos motivarmos e de gerir bem as emoções dentro de nós e nos nossos relacionamentos."

Para o autor, a Inteligência Emocional é a maior culpada pelo sucesso ou insucesso dos indivíduos. Em todas as áreas e na maioria das profissões há relacionamentos entre pessoas, sendo assim, indivíduos com competência na área de relacionamento humano - como afabilidade, compreensão e gentileza — têm maiores oportunidades de alcançar o sucesso.

Para o professor é importante o conhecimento desses novos estudos para que trabalhe por uma educação holística e para que nesse processo se perceba como alguém que precisa desenvolver tais competências, pois é mostrado em várias pesquisas que as crianças modelam o comportamento dos adultos. (ABED, 2016; COELHO E FIGUEIRA, 2011; COELHO, SOUSA E FIGUEIRA, 2014)

Motta et al (2006) pesquisou a relação entre as práticas educativas e os níveis de empatia em 77 crianças, com idades entre 6 e 12 anos. Destas, 37 viviam em abrigos, o restante dos participantes da pesquisa, 40 crianças residiam com as próprias famílias. As crianças que viviam em abrigos apresentaram escores inferiores aos das crianças que moravam com a família em termos de empatia quanto de práticas educativas. Estes resultados sugerem a existência de uma relação entre a forma como os pais educam os filhos e ou responsáveis e o desenvolvimento da empatia nas crianças. Então, há uma necessidade de ampliar a visão do professor, instrumentalizando-o para que as relações no espaço escolar sejam beneficiadas.

\section{HABILIDADES SOCIAIS}

As habilidades sociais podem assumir diversos significados a partir do aspecto teórica que se aborda. Nas últimas décadas, dentro da Psicologia, tem se ampliado uma área de investigação que busca estudar o desempenho social a partir de uma análise psicológica das interações sociais e das habilidades requeridas para 0 estabelecimento de relações e interações efetivas e de qualidade. Esta área tem sido 
denominada de campo teórico-prático das habilidades sociais (DEL PRETTE E DEL PRETTE, 2017).

De acordo com esta perspectiva teórica, o desempenho social pode envolver dois padrões distintos: (1) comportamentos não habilidosos e (2) comportamentos habilidosos socialmente. Os comportamentos não habilidosos são aqueles que possuem alta probabilidade de prejudicar a qualidade das relações interpessoais e pode envolver tanto relações não-habilidosas ativas, tais como agressividade física ou verbal, ironia, autoritarismo e coerção, como reações não-habilidosas passivas, as quais incluem mágoa, ressentimento, ansiedade e/ou esquiva ou fuga das demandas sociais ao invés do enfrentamento das mesmas (DEL PRETTE E DEL PRETTE, 2010; TURINI BOLSONI-SILVA E CARRARA, 2010).

Já os comportamentos habilidosos socialmente, denominados de habilidades sociais, são aqueles requeridos para a competência social, os quais são valorizados por uma dada cultura ou subcultura e que possuem alta probabilidade de gerar consequências positivas para a pessoa que os emite e para o grupo social no qual está inserida (DEL PRETTE E DEL PRETTE, 2010).

As habilidades sociais são comportamentos aprendidos ao longo do desenvolvimento do indivíduo (DEL PRETTE, FERREIRA, DIAS E DEL PRETTE, 2015) e sua aprendizagem depende das diferentes situações as quais uma pessoa é exposta ao logo da vida, proporcionado ou não condições para que tais habilidades sejam adquiridas e fortalecidas (DEL PRETTE E DEL PRETTE, 2009). Estudos têm apontado que em cada fase do desenvolvimento algumas classes de habilidades sociais parecem ser mais primordiais para a saúde e está compreendida como um estado de bem-estar físico, psicológico e social, que falhas no processo de aprendizagem das mesmas ou dificuldades para atender as novas demandas características de uma dada etapa vital podem causar ou estar relacionadas a déficits em habilidades sociais e a dificuldades de adaptação, produzindo consequências negativas sobre a saúde e a qualidade de vida do indivíduo (DEL PRETTE, FERREIRA, DIAS E DEL PRETTE, 2015). Assim, um repertório de habilidades sociais 
bem desenvolvido tem sido apontado como um fator de promoção da saúde e da qualidade de vida.

Os resultados encontrados por Silva, Bolsoni-Silva, Rodrigues e Capellini (2015) ilustram a relação entre habilidades sociais e promoção de saúde e qualidade de vida. Os autores buscaram correlações e predisposições entre as variáveis: condições de trabalho do professor, indicadores de Burnout, práticas educativas do professor e o repertório de habilidades sociais e de problemas de comportamento dos alunos. Participaram da pesquisa 94 professores de ensino regular de um curso de aperfeiçoamento (EAD), com turmas onde havia alunos com deficiência e/ou salas de recursos multifuncionais. Os resultados apontaram que práticas negativas, qualificados como comportamentos que não caracterizavam habilidade social, tem influência no nível de Burnout dos educadores, o qual é aparece ter influência das condições de trabalho.

Identificar o impacto específico de cada habilidade social sobre as dificuldades comportamentais, remete a buscar novos estudos na área, especialmente experimentais e longitudinais. Esses estudos são importantes para orientar o planejamento de intervenções mais focadas em determinadas classes de habilidades sociais necessárias a docência.

\section{FORMAÇÃO DE PROFESSORES}

Diante das crises no âmbito do saber e do fazer humano na área da Educação neste início de século, reavaliar, refletir sobre as habilidades e competências para ensinar, novos conceitos sobre como ensinar uma geração com características específicas, aprender a aprender no processo relacional da sala de aula, uma educação que atinja conceitos de autonomia, emancipação e liberdade. E principalmente uma educação que olhe para o professor como ser humano com necessidades e desejos que são frustrados no dia a dia das práticas escolares.

Essa mudança deve acontecer para que se possa compreender e ensinar a pensar sobre os problemas existentes, sobre as relações que estabelecemos nos diferentes 
contextos culturais, em uma sociedade que se transforma e é transformada nos seus processos de socialização e de formação de pessoas.

Assim, para Hermann (2001, p.90), "embora a sociedade imprima a Educação um caráter de constante mutação, como incontrolável, nós não devemos entender este processo como de desorientação". E por isso, neste contexto, torna-se impossível amparar um exemplo ideal de Educação e, muito menos, de se perpetuar práticas pedagógicas tradicionais.

Sendo assim, essa diversidade dos contextos sociais, que produzem e reproduzem pessoas com histórias e modos de agir e relacionar-se específicos, nos levam ao reconhecimento de uma pluralidade no ambiente escolar, que determina uma ação de educar onde priorize novos métodos e técnicas, que se renovam, e constantemente, reavaliam os objetivos da Educação.

Nos tempos atuais, espera-se que o papel do professor seja daquele que interfira, de forma ativa e repense sua prática, que garanta a formação de um educando autônomo, constante e responsável. Para isso é necessária uma reformulação dos cursos formadores de professores, capazes de formar um profissional facilitador da aprendizagem, prático e reflexivo, que envolva no processo educativo as necessidades e anseios dos alunos, proporcionando aos aprendizes realizações pessoais, profissionais e sociais. Este profissional da educação se organiza, auxilia e participa de todo o âmbito escolar que está inserido.

A educação brasileira vive um momento onde a necessidade de refletir sobre os investimentos feitos, na formação inicial de seus professores e ao longo de sua vida profissional, que seja efetiva e eficiente, para que possamos colher um produto final. Onde os valores de pátria, nação, tornarão nosso sistema educacional mais humano e humanizado, com modelos de vida mais dignos e responsáveis. (VASQUES E PALIPÉRIO, 2006)

De fato, este deveria ser a verdadeira função da escola e dos educadores: colaborar para uma vida melhor em todos os âmbitos da sociedade, diante da pluralidade 
existente, na busca de uma ação contínua de uma base epistemológica instrumentalizada da pedagogia, inter-relacionada com as demais ciências da educação, considerando o saber em toda sua extensão.

\section{CONSIDERAÇÕES FINAIS}

Se assim compreendermos e repensarmos a educação, poderemos desencadear um processo reflexivo das relações que são estabelecidas, através de uma prática educativa que interfira nas crenças e práticas docentes, como aprendizes e pesquisadores, em uma mistura de atitude para aprender e uma ação para promover.

Um professor reflexivo, que busca autoconhecer-se, acaba ampliando sua competência nas ações do fazer pedagógico. Aprender a ser, é uma competência que primeiro deve ser desenvolvida em si mesmo, para posteriormente ser aplicada e repassada ao outro. Assim, o erro e o sucesso fazem parte do crescimento, e na troca de experiências nos tornamos pessoas melhores. Nessa nova educação todos acendem juntos: professor, escola, sociedade.

Hoje criam-se muitas expectativas sobre o professor, e entre elas: afável da diversidade, aberto a mudanças, comprometido com a aprendizagem, aberto a uma real interação com seus alunos, formação adequada, dominando a língua materna, com conhecimentos tecnológicos, seja interdisciplinar no seu fazer, com saberes na área, que implemente projetos, uma pessoa que valorize quem aprende, desejando o sucesso do aprendiz. Enfim um sujeito construído na sua complexidade.

\section{REFERÊNCIAS}

ABED, A.L.Z. (2016). O desenvolvimento das habilidades socioemocionais como caminho para a aprendizagem e o sucesso escolar de alunos da educação básica. Constr. psicopedagógica. São Paulo, v. 24, n. 25, p. 8-2, 2016. 
BAUER, A., CASSETTARI, N. E OLIVEIRA, R.P. (2017). Políticas docentes e qualidade da educação: uma revisão da literatura e indicações de política. Ensaio: aval. pol. públ. Educ., Rio de Janeiro, v.25, n. 97, p. 943-970, out/dez.

CHIEN, W. T. (2008). Effectiveness of Psychoeducation and Mutual Support Group Program for Family Caregivers of Chinese People with Schizophrenia. The Open Nursing Journal, 2,28-39.

COBERO, C. P, R. MUNIZ, M. (2006). Inteligência emocional e desempenho no Trabalho: Um Estudo com MSCEIT, BPR-5 e 16PF. Paidéia (Ribeirão Preto), Ribeirão Preto, v 16, n. 35, dezembro.

COELHO, L.V.M. (2012). Competência Emocional em Professores: Contributos da Psicoeducação. Revista Portuguesa de Enfermagem de Saúde Mental, Porto, n. 8, p. 16-24, dez.

COSTA, A. C.; FARIA, L. (2009). A inteligência emocional no contexto de enfermagem: estudo exploratório com o questionário de competência emocional (QCE). Actas do X Congresso Internacional Galego-Português de Psicopedagogia. Braga: Universidade do Minho.

DEL PRetTe, A., E DEL PRETTE, Z. A. P. (2009). Componentes não verbais e paralinguísticos das habilidades sociais. Em DEL PRETTE, A E DEL PRETTE, Z.A.P. (Orgs.), Psicologia das habilidades sociais: Diversidade teórica e suas implicações (pp. 147-186). Petrópolis, RJ: Vozes.

DEL PRETTE, ZA.P.; DEL PRETTE. (2010). A. Habilidades sociais e análise do comportamento: Proximidade histórica e atualidades. Perspectivas, São Paulo, v. 1, n. 2, p. 104-115.

DEL PRetTe, Z. A. P., FerReiRA, B. C., DiAS, T. P., \& DEL PRetTE, A. (2015). Habilidades sociais ao longo do desenvolvimento: Perspectivas de intervenção em saúde mental. In Murta, S.G., Leandro-Grança, \& Santos K.B, (Eds.), Prevenção e 
promoção em Saúde Mental: Fundamentos, planejamento e estratégias de intervenção (pp. 318-340). Novo Hamburgo, RS: Sinopys.

DEL PRETTE, A. E DE DEL PRETTE, Z.A.P. (2017) Psicologia das habilidades sociais na infância: Teoria e prática. Rio de Janeiro: Editora Vozes Ltda.

ESTRELA, M. Profissão docente-dimensões afetivas e éticas. Coleção saberes plurais, coordenação Rosa Bizarro. Porto: Areal, 2010.

FERÁNDEZ-BERROCAL, P., EXTREMARA, N.(2002) Relation of Perceived Emotional Intelligence and Health-Related Quality of Life of Middle-Aged Women. Psychological Reports, Vol 91, Issue 1, pp. 47 - 59.

FERREIRA, A.B.H.(1986) Novo dicionário da língua portuguesa. Rio de Janeiro; Nova Fronteira.

FOCAULT, M. (1998). A ordem do discurso: aula inaugural no Collège de France, pronunciada em 2 de dezembro de 1970. Trad. Laura F. A. Sampaio. Campinas: Loyola.

FONSECA, L., VALLE, T. M., REIS, R. e Mesquita, K. (2016) Inteligência EmocionalUma Competência da Atualidade. XII Congresso Nacional de Excelência em Gestão e III Inovarse- Responsabilidade Social Aplicada. Rio de Janeiro: Universidade Federal Fluminese.

GARDNER, H. (2000). Inteligências Múltiplas: a teoria na prática. Artmed: Porto Alegre, 2000.

GOLEMAN, D.(1999) Trabalhando com a Inteligência Emocional. Rio de Janeiro: Objetiva.

GOLEMAN, D. (2006). Inteligência Social: o poder das relações humanas. Rio de janeiro: elsevier. 
GOLEMAN, D.(2012). Inteligência Emocional. Editorial Kairós, Barcelona (Es).

GOLEMAN, D. (2017). Inteligência Emocional: Mito X Fato. IT Management, 8 de agosto.

GOUVEA, L.A.V.N. (2016). As condições de trabalho e o adoecimento de professores na agenda de uma entidade sindical. Saúde Debate: Rio de Janeiro, v. 40, n. 111, p. 206-219, OUT-DEZ.

HERMANN, N.(2012). Pluralidade e Ética em Educação. Rio de Janeiro; DPZA Editora, 2001.IBGE, Instituto Brasileiro de Geografia e Estatística. Pesquisa Nacional de Saúde do Escolar: 2009. Rio de Janeiro: IBGE.

JOHNSON, S. M., Kraft, M. A., Papay, J. P. (2012). How context matters in high-need schools: The effects of teachers' working conditions on their professional satisfaction and their students' achievement. Teachers College Record, 114, 1-39.

LEHTINEN, V. (Coord.) (2008). Building up good mental health: Guidelines based on existing knowledge. Finlândia: Stakes.

MOTTA, D.C. et al. (2006) Práticas educativas positivas favorecem o desenvolvimento da empatia em crianças. Psicologia em Estudo, Maringá, v. 11, n. 3, p. 523-532, set./dez.

MORAES, S.P.G. et al.(2012). Pressupostos teórico-metodológicos para formação docente na perspectiva da teoria histórico-cultural. Revista Eletrônica de Educação. São Carlos, SP: UFSCar, v. 6, no. 2, p.138-155, nov.

RAHMANI, F., RANJBAR, F., EBRAHIMI, H, e HOSSEINZADEH, M. (2015). The effects of Group Psychoeducational Programme on attitude toward mental illness in families of patients with schizophrenia, 2014. Journal of Caring Sciences, 4(3),243251. 
ROSIN-PINOLA, A.R.; DEL PRETTE, Z.A.P. (2014). Inclusão escolar, formação de professores e a assessoria baseada em habilidades sociais educativas. Rev. bras. educ. espec., Marília, v. 20, n. 3, p. 341-356, Sept.

SILVA, N. R. da et al.(2015). O Trabalho do Professor, Indicadores de Burnout, Práticas Educativas e Comportamento dos Alunos: Correlação e Predição. Rev. bras. educ. espec., Marília, v. 21, n. 3, p. 363-376, Sept.

TURINII BOLSONI-SILVA V.A, CARRARA, K. (2010). Habilidades sociais e análise do comportamento: compatibilidades e dissensões conceitual-metodológicas. Psicol. rev. (Belo Horizonte), Belo Horizonte, v. 16, n. 2, p. 330-350, ago.

VALE, V. (2009). Do tecer ao remendar: os fios da competência socio-emocional. Exedra: Instituto Politécnico de Coimbra, no 2.

VASQUES, M.H.B.; Palipério, F.C.M.C. (2006); Competência e qualidade para ensinar. In: Educação: Pluralidade, Ética e Competência na Formação Profissionalizante Continuada dos Educadores. Disponível em: <www.hottopos.com>. Acesso em: 02 mar.

VEIGA-BRANCO, M. A. R. (2005). Competência emocional em professores- um estudo em discursos do campo educativo. Porto: Faculdade de Psicologia e Ciências da Educação. Tese de Doutorado. Tese de Doutoramento em Ciências da Educação.

VEIGA-BRANCO, A. (2009). Escala Veiga Branco das capacidades da inteligência emocional (EVBCIE): partes I e III .In Mendonça, S.S. Competências Profissionais dos Enfermeiros: a Excelência do Cuidar. Penafiel: Editorial Novembro. p. 162-164.

Enviado: Agosto, 2019.

Aprovado: Outubro, 2019. 